UDK 528.92

\title{
LIETUVOS ŽEMĖS PAVIRŠIAUS EROZIJOS MODELIAVIMAS IR KARTOGRAFAVIMAS TAIKANT GIS TECHNOLOGIJAS
}

\author{
Žydrūnas Dẻnass ${ }^{1}$, Algirdas Kumetaitis ${ }^{2}$, Saulius Šliaupa ${ }^{1}$, Algimantas Zakarevičius ${ }^{2}$, Rasa Šliaupienė ${ }^{3}$ \\ ${ }^{1}$ Vilniaus universitetas, Geologijos ir mineralogijos katedra, M. K. Čiurlionio g. 21/27, LT-03101 Vilnius, Lietuva, \\ el.paštas: zydrunas.denas@gmail.com, sliaupa@geo.lt \\ ${ }^{2}$ Vilniaus Gedimino technikos universitetas, Sauletekio al. 11, LT-10223 Vilnius, Lietuva, \\ el.paštas: kumetaitis@gmail.com \\ ${ }^{3}$ Geologijos ir geografijos institutas, T. Ševčenkos g. 13, LT-03223 Vilnius, Lietuva, \\ el. paštas: sliaupienė@geo.lt
}

Iteikta 200603 24, priimta 20060607

\begin{abstract}
Santrauka. Nuolatinis žemės paviršiaus plovimas ir su tuo susijusi dirvožemio erozija turi ịtakos žmogaus ūkinei veiklai, ypač žemès ūkiui. Tai lemia būtinybę ivvertinti erozijos pavojų tiek lokaliuoju, tiek regioniniu mastu. Erozija priklauso nuo daugelio veiksnių, kurių itaka taip pat nevienoda. Straipsnyje pateikiama erozijos potencialo skaičiavimo metodika, remiantis GIS sistemomis, ivvertinta erozijos rizika Lietuvos teritorijoje. Pradiniai parametrai pagrįsti daugiamečių lauko tyrimų rezultatais. Vieni iš pagrindinių veiksnių, lemiančiu skirtingą erozijos potencialą, yra paviršiaus litologija, dirvožemio sudètis, augmenijos tipas, - jie įvertinti modelyje. Ypač daug dèmesio skirta reljefo skaitmeninio modelio tobulinimui, nes reljefas yra vienas iš pagrindinių parametrų, lemiančių erozijos intensyvumą. Apskaičiuoti reljefo parametrai, tokie kaip šlaitų statumas, ekspozicija, polinkis. Modeliavimas parodė, kad paviršiaus erozijos didžiausios rizikos sritys yra Vakarų ir Rytų Lietuvos aukštumose.
\end{abstract}

Prasminiai žodžiai: erozija, dirvožemis, GIS, skaitmeninis reljefo modelis.

\section{Ivadas}

Dirvožemio erozijos mastą įvertinti svarbu planuojant žmogaus ūkinę veiklą, ypač žemès ūkyje. Paviršiaus nuplovimo mastui itakos turi daugelis veiksnių. Ankstesnieji Lietuvos erozijos modeliai buvo pagristi pusiau kiekybinių priemonių taikymu [1]. Šio darbo tikslas buvo sukurti metodiką, kuri leistų atlikti kompleksini erozijai ittakos turinčių veiksnių vertinimą. Pagrindiniai pradiniai duomenys apie vieno ar kito parametro itaką erozijos spartai gaunami atliekant lauko tyrimus poligonuose, esančiuose ivairiose Lietuvos vietose [2,3]. Pagrindiniai veiksniai, lemiantys dirbamos žemès plovimo ir erozijos mastą, yra dirvožemio tipas ir litologija, augmenija bei reljefas. Erozijos potencialo modelis buvo sudarytas taikant geografines informacines sistemas (GIS). Modelyje integruoti ir turiniu, ir forma skirtingi skaitmeniniai duomenys: CORINE žemès dangos GIS duomenu bazè, paviršiaus litologinis žemėlapis, sudarytas Lietuvos geologijos tarnyboje, bei reljefo skaitmeninis modelis (DTM, angl. Digital Terrain Model), sudarytas VI „GIS-Centras“. Modelis buvo gerokai patobulintas. Skaitmeniniai reljefo modeliai plačiai taikomi ne tik tokio pobūdžio tyrimams, jie vertingi ir sprendžiant daug kitų svarbių problemų [4-8].

\section{Erozijos potencialo priklausomybès}

Lietuvos dirvų erozijos rodiklis skaičiuojamas ivaairiais metodais, taip pat remiantis lauko tyrimu ir gamtinių procesu stebejimų duomenimis bei laboratoriniais tyrimais $[2,3]$. Erozijos koeficiento dydžiui ịtakos turi i̇vairūs veiksniai, jų poveikis nevienodas. Vienas iš reikšmingiausių yra reljefas. Šio veiksnio įtakos koeficientas gali būti izvertintas remiantis A. Račinsko (1990) pateikta priklausomybe:

$$
E_{T O P}=0,09 * l+1,62 * i+0,18 * e-1,46,
$$

čia $E_{T O P}$ yra erozijos potencialas $\left(\mathrm{m}^{3} / \mathrm{ha}\right), l$ - šlaito ilgis (m), $i$ - šlaito polinkio kampas (laipsniais), $e-$ šlaito ekspozicija (32 - rytinių šlaitu, 34 - vakarinių, $32-i$ šiauriniu, $32+i$ pietinių šlaitu).

Kiti svarbūs veiksniai yra litologija ir augmenijos tipas. Jų svoris įvertinamas [2]:

$$
E_{L C}=B *[1-(C-0,23)]
$$

čia $E_{L C}-$ litologijos ir augmenijos itaka erozijos potencialui, $B$ - paviršiaus litologijos veiksnys, $C-$ augmenijos veiksnys.

Klimato veiksniui $(K)$ visoje Lietuvoje taikyta ta pati konstanta $K=1$.

Suminis erozijos rodiklis skaičiuojamas integruojant aprašytuosius parametrus:

$$
E_{T O T A L}=E_{T O P} * E_{L C} * K
$$




\section{Metodai}

Erozijos potencialo modeliavimas buvo atliktas MapInfo Professional GIS programine iranga bei Vertical Mapper programine iranga, išplečiančia MapInfo funkcionalumą rastrinių GIS duomenų kūrimo ir analizès priemonèmis.

Erozijos potencialo modelis buvo kuriamas, remiantis rastriniu (reguliaraus tinklelio taškinès matricos) GIS duomenu modeliu. Atliekant kompleksini skirtingu parametru modeliavimą, visi skaitmeniniai duomenys pirmiausia buvo paversti vienos formos: vienodo duomenu formato (Vertical Mapper GRID), koordinačiu sistemos (LKS-94) bei rastrinių duomenu gardelès dydžio $(50 \times 50 \mathrm{~m})$.

Skaitmeninis reljefo modelis buvo sukurtas ESRI Arc/Info Workstation programine iranga. Arc/Info priemonèmis šie duomenys buvo transformuoti i $A S C I I$ GRID formata, o vèliau Vertical Mapper priemonėmis perkelti i MapInfo aplinką. Reljefo modelio gardelès dydis - $50 \mathrm{~m}$. Šio žingsnio buvo laikomasi atliekant ir visus tolesnius erozijos potencialo skaičiavimus.

Kiti pirminiai skaičiavimuose naudoti GIS duomenys buvo vektorinès formos. Perkelti i MapInfo formatą, šie duomenys buvo transformuoti i rastrinę formą, nustatant rastro gardelès dydi $50 \times 50$ metru. Duomenys transformuoti taikant Vertical Mapper Region to Grid funkciją.

Erozijos potencialo skaičiavimai atlikti dviem etapais. Pirmuoju etapu buvo įvertinta reljefo įtaka. Šlaito statumas ir kryptis apskaičiuoti iš skaitmeninio reljefo modelio, taikant Vertical Mapper komandą Create Slope \& Aspect. Šlaito statumas tolesniuose erozijos potencialo skaičiavimuose taikomas tiesiogiai. Skaičiuojant šlaito ekspozicijos veiksni reikia žinoti ir šlaito krypti, ir jo polinkio kampą. Šiauriniams, pietiniams, vakariniams ir rytiniams šlaitams (skirtinga ekspozicija) būdinga skirtingas erozijos potencialas. Taikant Grid Query funkciją pagal ekspozicijos rodikli buvo išskirstyti keturi šlaitu poaibiai. Apskaičiavus šlaito ekspozicijos veiksni kiekvienam posluoksniui, šie poaibiai sujungti, taikant Vertical Mapper Splicer komandą. Apytikslès šlaito ilgio Lietuvos teritorijoje reikšmès paimtos pagal [9].

Erozijos potencialas skaičiuotas Vertical Mapper priemonemis. Erozijos potencialas, kuri lemia reljefo veiksnys, buvo dauginamas iš erozijos potencialo reikšmių, susijusių su dirvožemio litologija ir augmenijos pobūdžiu. Tam tikslui buvo skaičiuojama kiekvieno veiksnio svarba (svoris). Taikant Grid Query funkciją, buvo išrinkti panašios svarbos tinklelio elementai. Nustatyta kiekvieno išrinkto poaibio atitinkama svarba (svoris). Poaibiai Vertical Mapper Splicer komanda buvo suvesti i vieną rastrini GIS duomenų sluoksni. Suminis erozijos potencialas pagal dirvožemio litologiją ir augmenijos tipą nustatytas, taikant Vertical Mapper Grid Calculator funkcijac.

\section{Pagrindiniai veiksniai, lemiantys erozijos} intensyvumą

\subsection{Reljefas}

Vietovès reljefas yra svarbus veiksnys erozijos intensyvumui [10-13]. Paviršiaus altitude Lietuvoje kinta nuo $0 \mathrm{~m}$ pajūryje iki beveik +300 m pietryčiuose. Rytinejje teritorijos dalyje skiriama Baltijos aukštuma, o vakaruose - Žemaitijos aukštuma (1 pav.). Tarp jų Vidurio Lietuvos žemuma.

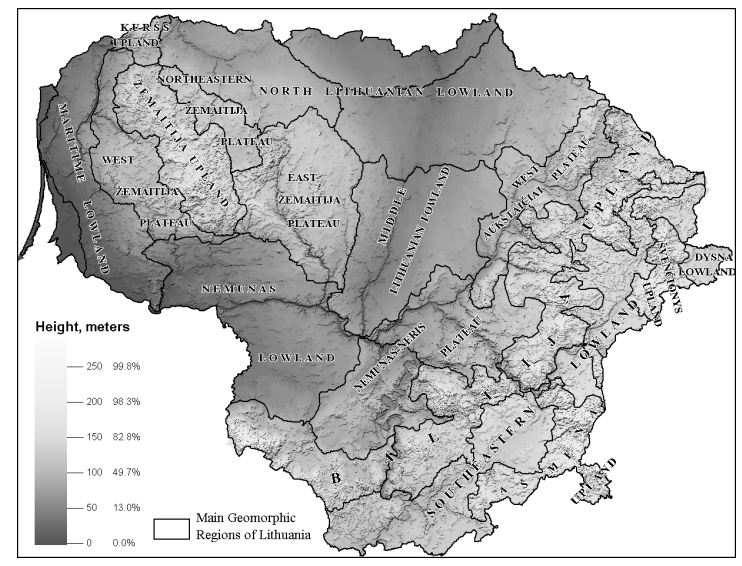

1 pav. Lietuvos reljefo skaitmeninis modelis ir pagrindiniai orografiniai rajonai

Fig 1. Digital terrain model and main geomorphic regions of Lithuania

Erozijos potencialui skaičiuoti naudota Lietuvos teritorijos skaitmeninio reljefo modelio (SRM) duomenys. Pirminiai SRM duomenys buvo VI „GISCentras“ 1996 m. pateiktas reljefo modelis. Šis modelis nepakankamai tikslus, ypač hidrografinių poligonu atžvilgiu, tad ji reikejo gerokai tobulinti. Tam tikslui iš 1:50 000 mastelio topografinių žemėlapių buvo papildomai digitalizuoti aukščių matavimo taškai ir panaudoti 1:200 000 bei 1:50 000 mastelių gravitacinio lauko matavimo taškų altitudžių duomenys.

SRM duomenų tikslumas analizuotas pagal topografinius taškus, digitalizuotus iš 1:10 000 mastelio kartografinių žemėlapių. Taškų tankis yra vienas taškas kvadratiniam kilometrui. Patikrinta daugiau kaip 64000 taškų visoje Lietuvos teritorijoje (žr. lentelę).

1999 m. SRM buvo patobulintas, papildant ji hidrografinio tinklo duomenimis (žr. lentelę). Ežerų poligonai prilyginti plokštiems paviršiams, o hidrografinių objektų kontūrai buvo prijungti kaip aukščių kontūrų linijos. Interpoliacija atlikta ANUDEM metodu (Australijos nacionalinis universitetas). ANUDEM metodu taikoma krigingo interpoliacija ir atsižvelgiama i hidrografines linijas bei poligonus. Taikant ši interpoliacijos metodą patikslinta Lietuvos teritorijos SRM, tačiau sritys šalia upių slennių su stačiais šlaitais liko problemiškos. Šioms vietoms detalizuoti papildomai buvo digitalizuota daugiau kaip 1600 tašku išilgai pagrindinių Lietuvos upių slènių. Atitinkamai perskaičiuota nauja SRM versija, i kurią itraukti 
Skirtingų metų Lietuvos SRM parametrai Parameters of Lithuanian DTM of different epochs

\begin{tabular}{|l|r|r|r|}
\hline $\begin{array}{l}\text { Statistiniai } \\
\text { duomenys }\end{array}$ & $\begin{array}{c}\text { SRM } \\
1996 \mathrm{~m} .\end{array}$ & $\begin{array}{c}\text { SRM } \\
1999 \mathrm{~m} .\end{array}$ & $\begin{array}{c}\text { SRM } \\
2000 \mathrm{~m} .\end{array}$ \\
\hline $\begin{array}{l}\text { Tašku } \\
\text { skaičius }\end{array}$ & 64451 & 64451 & 64450 \\
\hline Vidurkis & $-0,8$ & 0,0 & 0,5 \\
\hline Dispersija & 9,0 & 9,1 & 8,8 \\
\hline $\begin{array}{l}\text { Standartinis } \\
\text { nuokrypis }\end{array}$ & 3,0 & 3,0 & 3,0 \\
\hline Minimumas & $-27,0$ & $-27,0$ & $-29,0$ \\
\hline Maksimumas & 29,0 & 30,0 & 30,0 \\
\hline Asimetrija & 0,0 & $-0,1$ & 0,1 \\
\hline Perviršis & 5,6 & 4,5 & 4,9 \\
\hline
\end{tabular}

digitalizuoti taškai, aukščių kontūrų linijos ir taškai bei hidrografiniai poligonai. Pateikta SRM versija yra gerokai patikslinta, palyginti su 1996 m. versija (žr. lentelę). Galutinis Lietuvos teritorijos reljefo modelio patikslinimas atliktas, i SRM skaičiavimus papildomai ittraukus per 126 tūkstančius gravitacinio lauko taškų altitudžių.

Erozijos potencialui gauti taikyti trys reljefo parametrai: šlaito statumas, šlaito ekspozicija ir šlaito ilgis, apskaičiuoti pagal naują (patikslinta) SRM.

\subsection{Po dirvožemiu slūgsančių uolienų litologija}

Dirvožemio litologinė sudètis turi didelès itakos erozijos potencialui, nes skirtingi nuogulu tipai yra nevienodai atsparūs erozijai. Litologijos veiksnys buvo skaičiuojamas, remiantis kvartero Lietuvos geologiniu M 1:200 000 žemèlapiu [14].

Pagal dirvožemio sudèti išskirtos keturios klasès: (1) smèlingasis dirvožemis, (2) smèlingasis priemolis, (3) molingasis dirvožemis bei (4) durpès. Kiekvienai klasei priskirtas atitinkamas svoris erozijos procese [2]. Smèlingujų ir molingujų uolienų litologijos veiksnys priklauso ir nuo šlaito statumo. Smèlingosioms uolienoms būdingos didžiausiosios reikšmès $(1,5)$, jos susijusios su stačiais šlaitais $\left(>15^{\circ}\right)$, o mažiausiosios reikšmès $(0,7)$ būdingos lygumoms $\left(<3^{\circ}\right.$ polinkio $)$. Molingujų uolienų ši priklausomybè atvirkščia: didžiausiosios reikšmès $(1,4)$ būdingos lygumoms, o mažiausiosios $(1,1)$ nustatytos stačių šlaitų. Priesmèliui skirta reikšmė 1. Šio litologinio tipo atveju šlaito statumas neturi itakos. Durpynų erozijos potencialas paprastai esti nulinis, čia vyksta priešingas erozijai procesas - sedimentacija.

\subsection{Augmenijos tipas}

Augmenijos pobūdis lemia erozijos intensyvumą, nes augalija sumažina erozijos potencialą, palyginti su atviru dirvožemiu. Dangos veiksnys buvo skaičiuojamas remiantis Lietuvos teritorijos CORINE žemès dangos (mastelis 1:100 000) GIS duomenų baze [15, 16]. Visi dangos duomenys sugrupuoti i keturias klases: (1) mišku ir pievų, (2) sodų, (3) dirbamos žemès sričių (4) vietovių be augalinès dangos. Kiekvienai klasei suteiktos skirtingos reikšmès: miškams ir pievoms - 1; sodams 0,5; dirbamos žemès sritims - 0,25; vietovèms be augmenijos dangos (karjerai, išdegusios sritys, jūros pakrantès kopos ir kt.) - 0,1. Urbanizuotos sritys nebuvo ịtrauktos, nes jose dominuoja žmogaus veikla, kurios pobūdị sunku įvertinti.

\section{Modeliavimo rezultatai}

Kaip jau minèta, modeliavimas atliktas dviem etapais. Pirmiausia buvo îvertinta reljefo ittaka. Šlaitų statumas Lietuvos teritorijoje dažniausiai kinta $0^{\circ}-1^{\circ}$ intervalu (2 pav.). Statūs šlaitai (polinkio reikšmès siekia iki $19^{\circ}$ ) būdingi upių slèniams ir raižyto reljefo aukštumoms. Atitinkamai didesnis erozijos potencialas nustatytas vakarinejje ir rytinèje Lietuvos dalyje.

Ekspozicijos veiksnys kinta nuo 15 iki 45 (3 pav.). Vyraujančios reikšmès yra 32-33. Didesnès reikšmès būdingos Žemaitijos aukštumos vakariniam šlaitui ir Vidurio Lietuvos lygumos rytinei daliai.

Antruoju modeliavimo etapu buvo ivertinti dirvožemio litologijos ir paviršiaus dangos veiksniai. Dirvožemio veiksnys $(B)$ kinta priklausomai nuo uolienų litologijos, kuri savo ruožtu yra glaudžiai susijusi su reljefu. Didesnès (iki 1,5) reikšmès būdingos šiaurinei Lietuvos daliai, o minimalios $(0,7-0,8)$ vyrauja pietineje Lietuvos dalyje (4 pav.).

Erozijos potencialo reikšmès, priklausančios nuo reljefo veiksnio, dažniausiai yra $7-9 \mathrm{~m}^{3} /$ ha per metus. Didesnès reikšmès, viršijančios $10-15 \mathrm{~m}^{3} /$ ha per metus, būdingos aukštumoms (5 pav.). Didžiausiosios reikšmès - didžiujų upių slènių.

Paviršiaus dangos veiksnio svoris yra mažesnis, Lietuvos teritorijoje - 0,25-0,3. Sričių, kurioms būdingos didesnès (arti 1,0) reikšmès, pasitaiko rečiau, jos dažnesnès rytinëje ir pietrytinėje Lietuvos dalyje (6 pav.).

Apskaičiuotosios veiksnių skaitinès reikšmès buvo integruotos pagal anksčiau pateiktą lygtị. Suminis erozijos potencialas Lietuvos teritorijoje kinta nuo $0,12 \mathrm{~mm}$ iki 3,5 $\mathrm{mm}$ per metus (7 pav.). Mažiausios erozijos reikšmès ( $<1 \mathrm{~mm}$ per metus) nustatytos Rytų, Pietryčių, Pietvakarių ir Centrinèje Lietuvoje. Didelès erozijos reikšmès būdingos aukštumoms ir ypač upių slèniams (8 pav.).

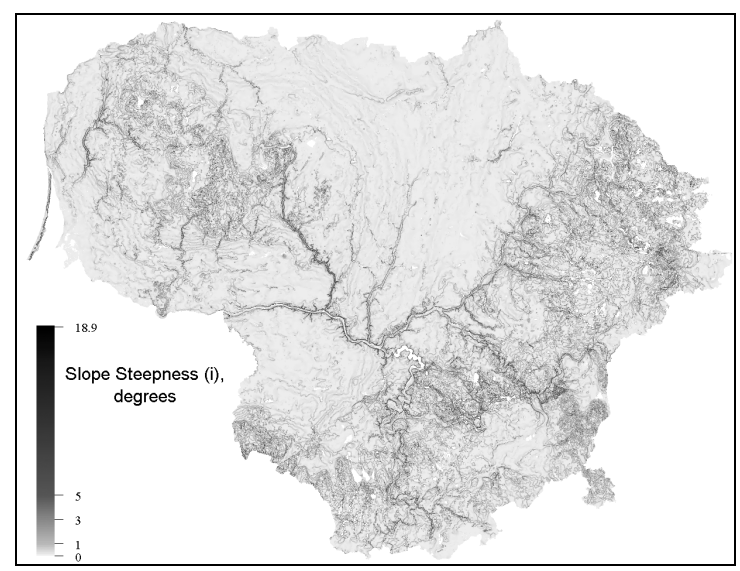

2 pav. Šlaitų statumo žemėlapis

Fig 2. Slope steepness factor 


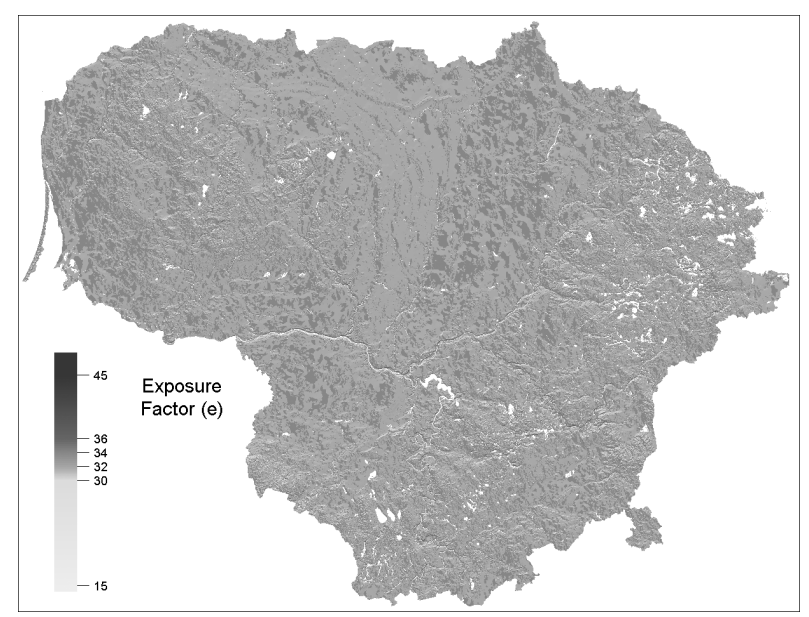

3 pav. Šlaitų ekspozicijos žemėlapis Fig 3. Slope exposure factor

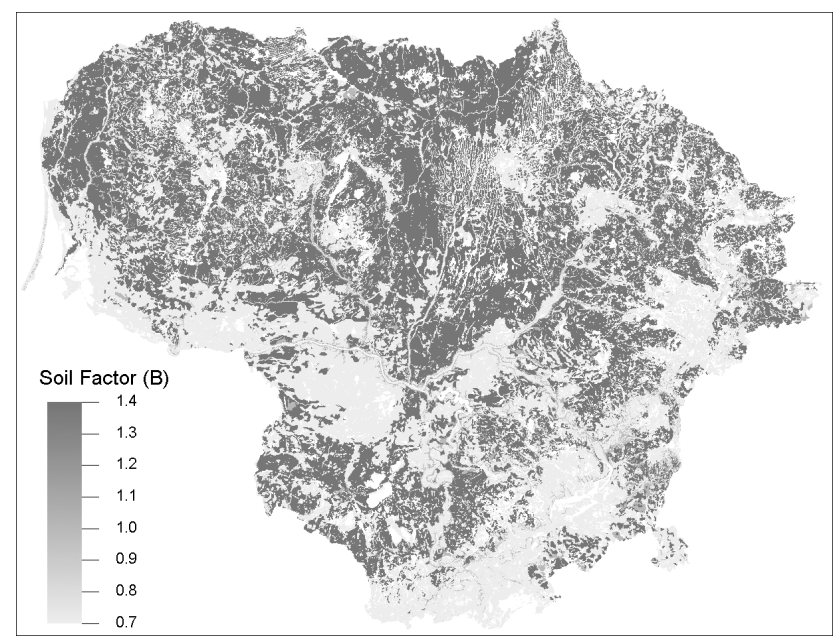

4 pav. Erozijos potencialo lygis, lemiamas dirvožemio litologijos veiksnio

Fig 4. Sub-soil lithology factor

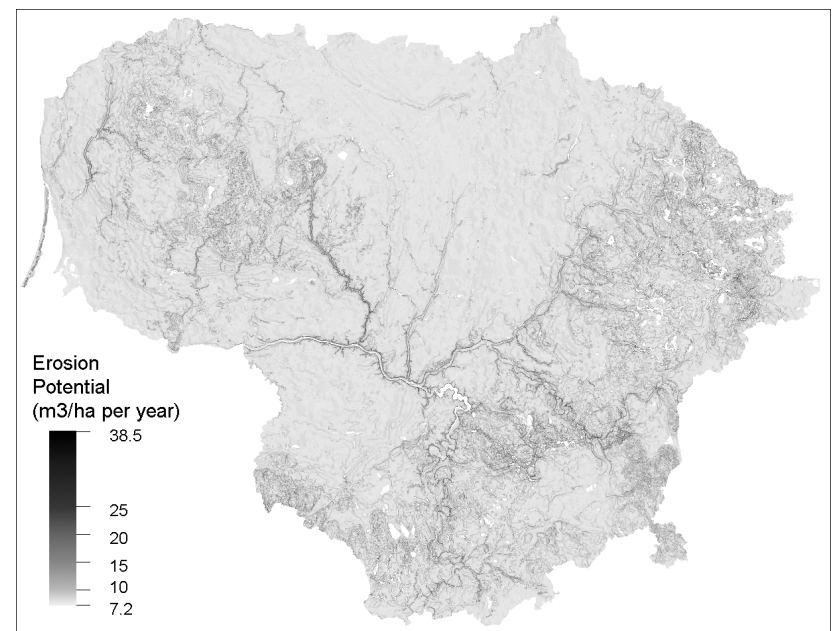

5 pav. Erozijos potencialas, susijęs su reljefo veiksniu Fig 5. Erosion potential, considered by topography factor

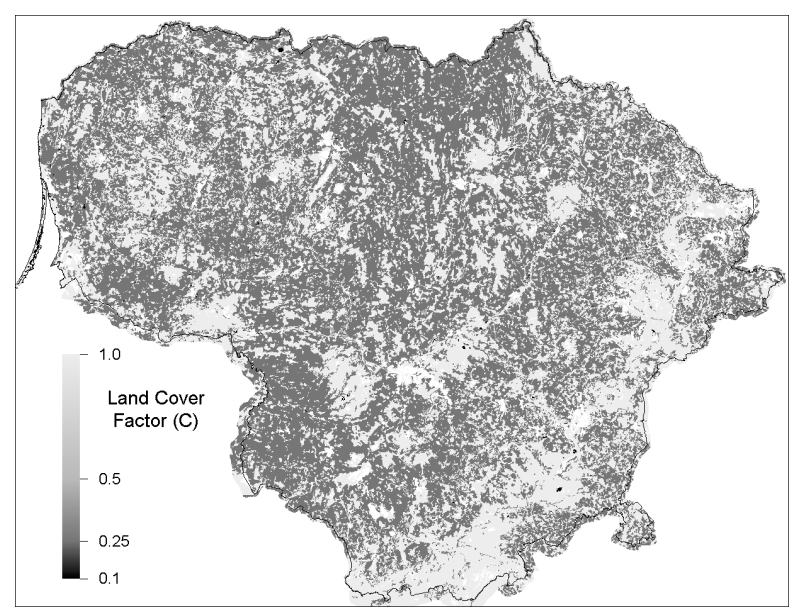

6 pav. Erozijos potencialas, nulemtas paviršiaus dangos veiksnio

Fig 6. Land cover factor

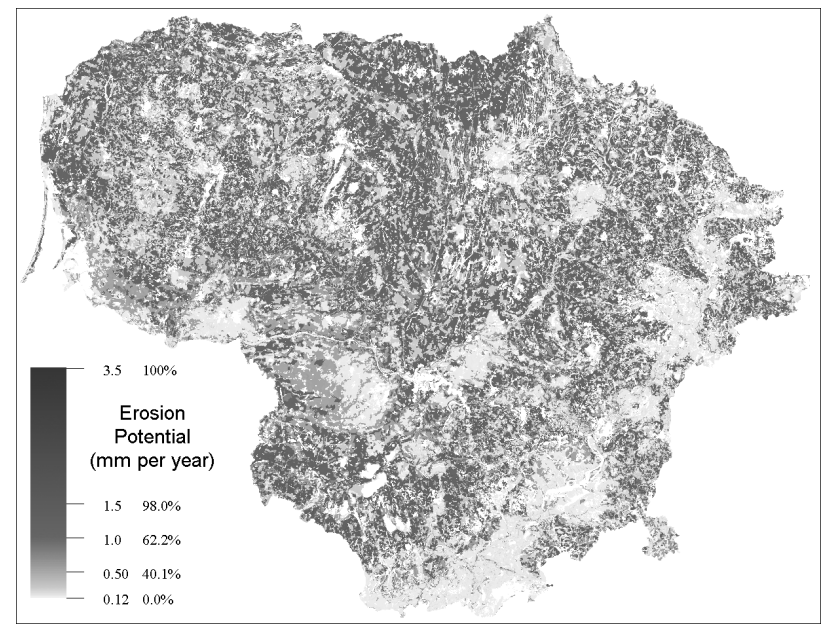

7 pav. Lietuvos erozijos potencialas

Fig 7. Erosion potential of Lithuania

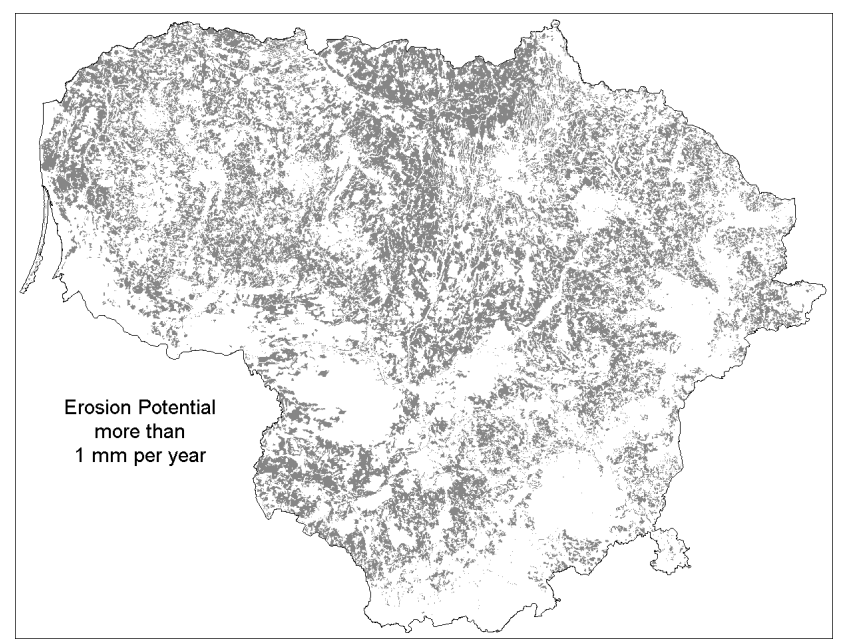

8 pav. Teritorijos, kuriose erozijos potencialas viršija $1 \mathrm{~mm} / \mathrm{m}$ Fig 8. Erosion potential higher than $1 \mathrm{~mm}$ per year 


\section{Išvados}

Taikyti GIS, modeliuojant erozijos potenciala, labai efektyvu. Pagrindinis šio metodo privalumas yra rezultatu tikslumas, nepaisant nagrinejjamos teritorijos dydžio, duomenu kiekio ir veiksniu gausos. Tikslumas priklauso tik nuo pradinių duomenų tikslumo [17]. Veiksnių itakos ivvertinimo tikslumą lemia parametrų nustatymas pagal lauko bandymų, stebejjimų bei laboratorinių eksperimentų rezultatus. Taigi modeli galima nesunkiai atnaujinti, atsiradus daugiau duomenu.

Apskaičiuotasis modelis rodo žymius ivvairių Lietuvos vietu erozijos potencialo skirtumus. Erozijos reikšmès kinta nuo $0,1 \mathrm{~mm}$ iki $3,5 \mathrm{~mm}$ per metus. Mažiausiosios erozijos reikšmès $(<1 \mathrm{~mm}$ per metus) nustatytos Rytu, Pietryčių, Pietvakarių ir Centrinejje Lietuvoje. Didžiausiosios reikšmès būdingos aukštumoms ir ypač upių slèniams.

\section{Padèka}

Ž. Dėno darbas yra dalis jo doktorantūros darbo Vilniaus universitete. A. Kumetaičio tyrimai doktorantūros studijų Vilniaus Gedimino technikos universitete dalis.

\section{Literatūra}

1. Česnulevičius, A. Intensity of the geodynamic processes affecting the Lithuanian relief. Litosfera, No 2. Vilnius: Institute of Geology, 1998, p. 157-164 (in Lithuanian).

2. Račinskas, A. Soil erosion (Dirvožemio erozija). Vilnius: Mokslas, 1990. 135 p. (in Lithuanian).

3. Jankauskas, B. Soil erosion (Dirvožemio erozija). Vilnius: Margi raštai, 1996. 167 p. (in Lithuanian).

4. Pennock, D. J.; Zebarth, B. J.; De Jong, E. Landform classification and soil distribution in hummocky terrain, Saskatchewan, Canada. Geoderma, Vol 40 (3-4), 1987, p. 297-315.

5. Moore, I. D.; Gessler, P. E.; Nielsen, G. A.; Peterson, G. A. Soil attribute prediction using terrain analysis. Soil Science Society of America Journal, 57 (2), 1993, p. 443-452.

6. Beven, K. J.; Lamb, R.; Quinn, P.; Romanowicz, R.; Freer, J. Topmodel. In: Singh, V. P. (Ed.), Computer Models of Watershed Hydrology. Colorado: Water Resources Publications, 1995. 1144 p.

7. Le Bissonnais, Y.; Montier, C.; Jamagne, M.; Daroussin, J.; King, D. Mapping erosion risk for cultivated soil in France. Catena, No 46, 2001, p. $207-$ 220.

8. Florinsky, I. V.; Eilers, R. G.; Manning, G. R.; Fuller, L. G. Prediction of soil properties by digital terrain modeling. Environmental Modelling \& Software, No 17, 2002, p. 295-311.

9. Česnulevičius, A.; Minkevičius, V.; Mikalauskas, A.; Biaconis, M.; Mikutienè, L. Morphometry of Lithuanian SSR. Geographia Lithuanica (Geografijos metraštis), Vol 17. Vilnius, 1984, p. 36-42 (in Russian).
10. Jenny, H. Derivation of state factor equations of soils and eco-systems. Soil Science Society of America Proceedings, Vol 25 (5), 1961, p. 385-388.

11. Huggett, R. J. Soil landscape systems: a model of soil genesis. Geoderma, Vol 13 (1), 1975, p. 1-22.

12. Gerrard, A. J. Soils and Landforms. In: An Integration of Geomorphology and Pedology. London: George Allen and Unwin, 1981. $219 \mathrm{p}$.

13. Gessler, P. E.; Moore, I. D.; McKenzie, N. J.; Ryan, P. J. Soil-landscape modelling and spatial prediction of soil attributes. International Journal of Geographical Information Systems, Vol 9 (4), 1995, p. 421-432.

14. Guobyte, R. Geological map of Lithuanian quarter. Geological horizonts (Geologijos akiračiai), Vol 1/99, 1999, p. 7-16 (in Lithuanian).

15. EEC, CORINE soil erosion risk and important land resources in the southern regions of the European Communities. Brussels, 1992. 97 p.

16. EEC, CORINE Land Cover. Guide technique. Brussels, 1993. $144 \mathrm{p}$.

17. King, D.; Fox, D.; Daroussin, J.; Le Bissonnais, Y.; Daneels, V. Upscaling a simple erosion model from small area to a large region. Nutr. Cycling Agroecosyst., Vol 50, 1998, p. 143-149.

Saulius ŠLIAUPA. Doctor Habil. Vilnius University. Dept of Geology and Mineralogy, M. K. Čiurlionio g. 21/27, LT-03101 Vilnius, Lithuania ( $\mathrm{Ph}+3705210$ 4698,

Fax +370 5210 4695), e-mail: sliaupa@geo.lt.

Published 3 monographs, more than 100 scientific papers, participated in many intern conferences.

Research interests: regional geology, tectonics, geodynamics, lithology, petrophysics.

Žydrūnas DE்NAS. MSc. Vilnius University. Dept of Geology and Mineralogy, M. K. Čiurlionio g. 21/27, LT-03101 Vilnius, Lithuania $(\mathrm{Ph}+3705239$ 8200, Fax +370 5239 8204), e-mail: z.denas@it.lt.

$\mathrm{PhD}$ student of the Dept of Geology and Mineralogy of the Vilnius University, Lithuania. Published several publications, participated in some intern conferences.

Research interests: application and development of GIS systems.

Rasa ŠLIAUPIENĖ. MSc. Institute of Geology \& Geography, T. Ševčenkos g. 13, LT-03223 Vilnius, Lithuania $(\mathrm{Ph}+3705210$ 4690, Fax +370 5210 4695),

e-mail: sliaupiene@geo.lt.

Junior Research Associate of the Department of Bedrock Geology of the Institute of Geology \& Geography, Lithuania. Published several publications.

Research interests: regional geology.

Algirdas KUMETAITIS. MSc. Vilnius Gediminas Technical University. Dept of Geodesy and Cadastre, Sauletekio al. 11, LT-10223 Vilnius, Lithuania ( $\mathrm{Ph}+370699$ 23308),

e-mail: kumetaitis@gmail.com.

Senior GIS engineer UAB "Bitė Lietuva", Lithuania. Published several publications.

Research interests: digital terrain modeling, development of GIS systems. 